\title{
Drugs on clinical development for the treatment of amyotrophic lateral sclerosis
}

\author{
Ana Martinez, 'Valle Palomo, Daniel I Perez, Carmen Gil,
}

Centro de Investigaciones Biologicas-CSIC, Ramiro de Maeztu 9, 28040 Madrid, Spain

Correspondence to:

Prof. Ana Martinez

Centro de Investigaciones Biologicas-CSIC

Ramiro de Maeztu 9

28040 Madrid, Spain

Tel.: +34 918373112 ext 4437

e-mail: ana.martinez@csic.es

\begin{abstract}
Introduction: Amyotrophic Lateral Sclerosis (ALS) is a fatal motor neuron progressive disorder for which no treatment exists up to date. However, there are some investigational drugs and therapies under clinical development that may offer some hope in the near future

Areas covered: We have revised all the ALS ongoing clinical trials (until November 2016) and collected in Clinical.trials.gov or EudraCT. We have described them in a comprehensive way and grouped them in the following sections: biomarkers, biological therapies, cell therapy, drug repurposing and new drugs.

Expert Opinion: Despite the multiple obstacles that explain the absence of effective drugs for the treatment of ALS, joint efforts among patient's associations, public and private sectors have fueled innovative research in the field, resulting in several compounds that are in the late stages of clinical trials. Drug repositioning is also playing an important role, having achieved the approval of some orphan drug applications, in late phases of clinical development. Endaravone has been recently approved in Japan and is pending in USA.
\end{abstract}

Keywords: ALS, new drugs, clinical trials, cell therapy, biomarkers 


\section{Introduction}

Amyotrophic Lateral Sclerosis (ALS), also known as Lou Gehrig's or Charcot disease, is a late-onset fatal motor neuron progressive disorder that leads to muscle deterioration and paralysis. The incidence of ALS is around two to three people per year out of 100,000 of the general population , being classified as a rare disease . However, ALS is the third prevalent neurodegenerative disease, affecting 150,000 people in the world [1].

The rate at which ALS progresses can vary from one person to another. Although the mean survival time is three to five years, many patients can live over five to ten years and even over ten . Sporadic ALS (90-95\%) constitutes the large majority of cases, while the remaining $5-10 \%$ of the patients are affected by the hereditary form termed familial ALS. Both sporadic and familial ALS are associated with cortical and spinal motor neuron degeneration [2]. The etiology of ALS remains unknown and the exact mechanisms of ALS pathogenesis are not fully understood yet . However some pathological pathways comprising of glutamate excitotoxicity, oxidative stress, microglia activation, ion channel and mitochondria dysfunction, apoptosis and different proteinopathies are signatures of this disorder [3]. To this date, ALS is not a curable disease and does not have an effective treatment. Current treatment regimens are largely only focused on relieving symptoms to improve the quality of life of those affected [4].

Riluzole remains the only approved therapy available for patients with ALS and shows a very modest efficiency on decelerating the progression of the disease, being more effective in early affected patients [5]. Although it is recognize $d$ to decrease the neurotoxic effect of glutamate [6], its mechanism of action remains largely unknown and the efficiency of drugs is needed urgently by both patients and their families Different obstacles prevent the progress and translation of new drugs from the bench to the patients, being the lack of suitable animal models one of them [7]. Although some of them mimic several aspects of the disease, no animal model fully replicates the spectrum of phenotypes encountered in the human disease, making it difficult to assess how a therapeutic effect observed in disease models could predict the efficacy in humans. Importantly, the genetic and phenotypic heterogeneity of ALS leads to a variety of responses to similar treatment regimens [8]. However, r ecent knowledge in the molecular pathways behind ALS together with new trends in clinical trial design $s$ has provided hope for effective therapies in the future $[9,10]$.

This review tries to summarize current drugs and/or therapies in clinical trials for ALS, 
as a lookout on the next potential generation of effective treatments. It is focused on several trials listed on PubMed Central and/or the National Institutes of Health and European Medicinal Agency online trial registry. Less than a hundred open clinical studies have been identified. These may be divided into observational and interventional studies. The first ones include not only the buildup of different patient 's registries but also clinical research aimed to identify new ALS biomarkers using imaging techniques. Only 48 ongoing registered studies are interventional, and they are focused on increasing the patient's quality of life (Table 1) or on the development of alternative therapeutic approaches. Among the last ones, several strategies are found based on cell therapies, biologicals, repurposing of approved drugs with a mechanism of action compatible with ALS pathobiology and very few new drugs that may alleviate or stop ALS progression.

Here, Table 1

\section{New ALS biomarkers in clinical studies}

Currently there is a lack of useful biomarkers in ALS. This cause $s$ a diagnostic delay among other issues, from the time of first symptoms to first medical consultation or initial evaluation of more common disorders [11], and the impossibility of proper patient classification in order to identify those that may respond better to a particular drug. For this reason multiple drugs have failed for ALS treatment as they have been administered in the late stages of the disease. Although today the diagnosis is based on the opinion of an experienced neurologist assessment and on electromyogram investigation with accepted criteria, in the last decade there has been a huge interest in discovering biomarkers for this disease.

A biomarker is defined as a characteristic that is objectively measured and evaluated as an indicator of normal biological processes, pathologic processes, or biological response to a therapeutic intervention" [12].

Today different biomarkers ha ve emerged such as biological fluid-based (e.g. CSF superoxide dismutase 1 levels, phosphorylated neurofilament light chain, urinary p75NTR ${ }^{E C D}$ ), neuroimaging techniques (e.g. magnetic resonance imaging, positron emission tomography) and electrophysiological parameters (e.g. electrical impedance myography) among others [13].

In the following paragraphs, we will report the different clinical studies aimed to identify and/or validate biomarkers ongoing for ALS (Table 2).

2.1 Flutriciclamide $\left({ }^{18} \mathrm{~F}-\mathrm{GE}-180\right)$ is a recently developed third generation $18 \quad \mathrm{kDa}$ 
translocator protein (TSPO) used as in vivo marker of neuroinflammation [14]. The TSPO receptor, also called the peripheral benzodiazepine receptor (PBR), is one of the most studied biomarkers of neuroinflammation $[15,16]$. The aim of this trial, in which around 200 participants will be enrolled, is to determine systemic inflammatory factors that may modify the progression of the disease or other clinical or imaging correlates of ALS. These structural or anatomical changes can be observed in the brain via magnetic resonance imaging (MRI) comparing ALS patients with healthy controls. Additionally blood samples will be studied in order to quantify pro- and anti-inflammatory monocyte/macrophage and T cells comparing these results with neuroimaging assessment and evaluated as potential biomarkers of disease progression. The study is now recruiting participants and it is being developed by Massachusetts General Hospital (Clinicaltrial.gov NCT02559869).

2.2 $\left[{ }^{18} \mathrm{~F}\right] \mathrm{T} 807$ is a Positron Emission Tomography (PET) radiotracer developed for imaging tau protein aggregates, which are implicated in ALS [17] and other neurological diseases such as Alzheimer's disease or traumatic brain injury . PET radiotracers provide in vivo pathophysiological information in human subjects. Selective tau radiotracers allow the non-invasive monitoring of tau pathology providing better understanding of tau aggregation in the brain [18]. The main goal is to evaluate tau distribution in the brain in ALS patients and normal controls. The study is in clinical phase II ( Clinicaltrial.gov NCT02414230) and is being developed by Washington University School of Medicine.

2.3 MRI Biomarkers in ALS. This study, currently ongoing in the University of Alberta, is using advanced Magnetic Resonance Imaging (MR I) techniques to measure brain changes in ALS patients and other related neurological conditions (Clinicaltrial.gov NCT02405182). Results from cognitive and neurological tests will be compared to the MRI. It is expected that these techniques will reveal changes in the brain that will help understand normal brain function and the symptoms of neurological diseases observed in ALS, providing as well an objective measurement of degeneration. This outcome could improve not only the process by which new drugs for the treatment of neurological diseases are evaluated, but also how health care professionals address the needs of patients with these diseases.

\subsection{Combination of Multiparametric MRI and Electrophysiology for the} Development of New Biomarkers in Spinal Cord Diseases. This study which is currently being recruiting around 100 participants is being developed by the Institut de Recherche sur la Moelle épinière et l'Encéphale (Clinicaltrial.gov NCT02885870) in 
order to diagnose and monitor different neurodegenerative diseases related to spinal cord such as spinal muscular atrophy (SMA), ALS or X-linked spinal bulbar muscular atrophy (SBMA). The main goal is to obtain specific biomarkers of white and grey matter degeneration by a combination of MRI and electrophysiology through the study of these diseases.

By combining these techniques for the investigation of human spinal cord in vivo, the goal is to extract new biomarkers to use them as study models. Diseases of the spinal cord affect different the white and the grey matter (SMA, SBMA and ALS) (NCT02885870).

\subsection{Non-invasive Assessment of Neuronal Damage by MRI Sodium (23 $\mathrm{Na}$ ) in}

ALS, (Clinicaltrial.gov NCT02874209) is another active clinical trial which is recruiting participants. The study is sponsored by Assistance Publique Hopitaux De Marseille and it is based on the employment of sodium MRI as an effective and sensitive biomarker for detecting and quantifying neuronal degeneration in different diseases such as multiple sclerosis [19], Alzheimer's disease [20] and Huntington 's disease [21] are among others.

Based on the reported studies that the levels of IFN- yare increased in bot $\mathrm{h}$ CSF and serum of ALS patients [22, 23], a clinical trial (Clinicaltrial.gov NCT02424669) started in May 2015 sponsored by Assistance Publique Hopitaux De Marseille. The main goal of the study, which is recruiting participants, is to analyse if IFN- $\gamma$ might have a role in the pathogenic process of ALS and might be a potential biomarker of the disease.

Here, Table 2

\section{Cell therapies}

Given the great need for an effective ALS therapy some alternative approaches to small molecules such as cell therapies are being studied. Stem cell therapy offers a therapeutic alternative in which pluripotent cells can migrate to disease lesions [24] and provide protective factors to surrounding cells, inhibit inflammation or replace damaged cells [25].

The majority of the ongoing cell therapy clinical trials for ALS are centered in autologous (self) transplantation, which would prevent immune rejection. Cell therapeutic studies highlight non-neuronal cells due to the progressive degeneration nature of the disease on motoneurons and other neural cells. Specifically mesenchymal stem cells derived from adipose or bone marrow tissue are the most studied in clinical 
trials at the moment since there is evidence that ALS does not affect

this cellular population [26]. Their multipotency, multifactorial mechanisms of action, relatively easy extraction and proved safety and injection feasibility [27-29] in patients have contributed to study their potential benefits in the clinic. In order to avoid invasive strategies such as direct transplantation, the injection of these cells is currently being examined as a new strategy of delivery to the central nervous system. There are currently 3 phases I and 2 phases I/II cellular studies ongoing (Table 3). The optimal strategy to deliver stem cells to the nervous central system in patients with ALS has not been discovered yet and the ongoing clinical studies explore different methods of administration: intravenous, intrathecal and intramuscular injection. A report published detailing the results of Corestem clinical trials highlights the safety of intratechal administration of stem cells, however the study of their efficacy remains yet to be disclosed [30].

In the attempt of finding other non-neuronal cells that could be transplanted to ALS patients and provide clinical benefit human glial restricted progenitor cells have been studied. These direct interventions show neuroprotection in mice however more studies are needed to establish whether they could contribute to a clinical benefit in patients [31].

When the use of stem cells is considered as a new treatment, the complexity of the clinical trial design is increased due to heterogeneity of these cells, limited knowledge about optimal dosing or way of delivery among other issues. All these points were agreed recently [32] to address key translational barriers for further phase II/III trials.

Another interesting therapy under research is based on engineered cells capable of secreting diverse factors beneficial for the neurons affected by the disease. In this area there are 2 phase II studies sponsored by BrainStorm-Cell therapeutics (Clinicaltrial.gov NCT02017912) in collaboration with Hadassah Medical Organization (Clinicaltrial.gov NCT01777646) to prove safety and efficacy of the trademarked cells "NurOwn". These autologous engineered cells are expected to support neurons by secreting neurotrophic factors. Preliminary results of one of the phase II clinical trials shows the safety of intramuscular and intrathecal administration of these engineered cells with possible benefits for ALS patients to be more extensively studied in further upcoming clinical trials [33]. Another phase I study conducted by Cedars-Sinai Medical Center, USA (Clinicaltrial.gov NCT02943850) currently in phase I studying the safety of genetically modified progenitor cells that express GDNF.

Here, Table 3 


\section{Biological drugs for ALS}

A mutation in the SOD-1 gene results in an inherited form of ALS, referred to as SOD1ALS. SOD1-ALS is the second most common familial form of ALS, accounting for up to 20 percent of familial ALS. The antisense drug designed to reduce the production of superoxide dismutase 1 (SOD1) called BIIB067 (Isis-SOD1Rx) is in clinical trials phase I to evaluate the safety, tolerability, and pharmacokinetics (PK) in adults with ALS (Clinicaltrial.gov NCT02623699). Previously, and after an intraventricular infusion, it has shown a decrease in SOD1 mRNA and protein concentrations in spinal cord tissue, and prolonged survival after its delivery to CSF in the SOD1 Gly93Ala rat model of ALS [34]. The first-in-human trial was recently reported after intratechal administration, with no recorded dose-limiting toxic effects or any safety or tolerability concerns [35].

The Barrow Neurological Institute is currently recruiting participants for a trial using Tocilizumab in ALS ( Clinicaltrial.gov NCT02469896). Tocilizumab is a monoclonal antibody that antagonizes interleukin-6 receptor. It was approved in 2009 (EMA) and 2010 (FDA) for the treatment of rheumatoid arthritis after its proved efficacy as to reduce inflammation in patients and slow disease progression [36]. The current phase II clinical trial focuses on safety and tolerability of the drug and additionally efficacy and target engagement will be assessed as secondary outcome measures.

Another monoclonal antibody tested in ALS patients is ozanezumab, that targets the neurite outgrowth inhibitor, Nogo-A, overexpressed in ALS patients [37]. After having positive results in SOD mice model that showed disease progression delay after antibody administration [38] a phase I clinical trial was performed to evaluate safety and tolerability. It finished in 2011 demonstrating that ozanezumab was well tolerated and safe for patients [39], and that further studies were required to assess efficacy. However in 2015 results from the phase II clinical trial showed no improved efficacy compared to placebo treated patients, highlighting the difficulties of translating research results to patients.

\section{Drug repurposing}

Finding new uses for existing drugs, the so called drug repurposing strategy is a fruitful method to discover and develop new drugs for rare diseases. Several approved drugs for many different medical needs are currently in clinical development for ALS (Figures 1 and 2).

5.1 Triumeq ${ }^{\circledR}$. This antiretroviral, an HIV medication, is now investigated in a phase lla 
open-label study to determine its safety and tolerability in Motor Neuron Disease (MND)/ALS patients, sponsored by Neuroscience Trials Australia (Clinicaltrial.gov NCT02868580). The clinical trial of Triumeq, that combines in a single-tablet the integrase strand transfer inhibitor dolutegravir and the nucleoside/nucleotide reverse transcriptase inhibitors abacavir and lamivudine, is recruiting participants. Previous studies had shown reverse transcriptase in serum of ALS patients at levels comparable to HIV-infected patients [40], and the expression of a human endogenous retrovirus (HERV) was confirmed in brain tissue autopsy of patients with ALS [41]. T he relationship between ALS and HERV has gained importance in the pathophysiology of this neurodegenerative disease being the rationale behind this open trial $[42,43]$.

\section{Here, Figure 1}

5.2 Ibudilast (MN-166), a well-known phosphodiesterase 4 (PDE4) inhibitor approved for the treatment of Chronic Obstructive Pulmonar Disease (COPD), is being administered in a Phase II study to evaluate safety and tolerability versus placebo when administered with riluzole in ALS patients (Clinicaltrial.gov NCT02238626). Moreover, a study to see the effect on several markers of neuro-inflammation measured by blood biomarkers after treatment with Ibudilast is also ongoing

(Clinicaltrial.gov NCT02714036). Targeting PDE4, Ibudilast is able to increase cAMP levels that modulate inflammation and microglia activation conferring neuroprotective activity [44]. The two ongoing clinical trials are sponsored by the biopharmaceutical MediciNova, Inc. (USA) and final results are expected by December 2017. In November 2016, according to MediciNova media release, European Medicines Agency recommended orphan medicinal product designation for MN-166 ( ibudilast) for Amyotrophic Lateral Sclerosis (http://adisinsight.springer.com/trials/700248663).

5.3 T amoxifen. After the serendipitous finding that ALS patients with breast cancer treated with tamoxifen seemed to improve neurologically, and that it was somehow responsible for reducing the rate of progression [45], preliminary evidences suggested that tamoxifen might be neuroprotective in stroke and hypoxia [46]. This drug is an estrogen-receptor modulator (SERM), but its neuroprotective action looks to be related to its ability to inhibit protein kinase $C$, which is increased in the spinal cord of ALS patients [47]. More recently, tamoxifen has been discovered as an autophagy modulator being able to modulate the main proteinopathy present in ALS, the TAR DNAbinding protein 43, in animal models [48]. Based on th ese findings, a phase II study in ALS patients treated with riluzole and also with tamoxifen was started in 2014 sponsored by Taipei Medical University Shuang Ho Hospital (Taiwan), although no 
updates have been posted (Clinicaltrial.gov NCT02166944).

5.4 Mexiletine. Motor neuron hyperexcitability appears to be linked to the process of neurodegeneration in ALS. As such, therapies that inhibit neuronal hyperexcitability may prove effective in arresting the progression of ALS [49]. That is the case of $t$ he antiarrhythmic drug Mexiletine, a sodium channel blocker. It was used in a phase II double-blind randomized controlled trial of sporadic ALS, sponsored by the University of Washington (USA), to determine safety and tolerability due to its ability to reduce hyperexcitability, a potential early step in the disease (Clinicaltrial.gov NCT01849770). The drug was safe when given daily to ALS patients at 300 and $900 \mathrm{mg}$ and welltolerated at the lower dose. The treatment resulted in large dose-dependent reductions in muscle cramp frequency and severity. No effect on $r$ ate of progression was detected although clinically important differences may not be excluded due to the short-duration of the study [50].

5.5 Ezogabine (retigabine) was approved for the treatment of partial epilepsy and its mechanism of action is due to its ability to bind the voltage-gated potassium channels and increase the M-current thereby cau sing membrane hyperpolarization [51]. Data supports the hypothesis that neurons become hyperexcitable in ALS, firing more than they normally do, which may contribute to nerve cell death. This is considered a root cause and/or effect of ALS/MND. In patient-derived motor neurons , ezogabine has shown the ability to reduce excitability and prolong motor neuron survival [52]. For this reason, a Phase II study was initiated to evaluate the effect of ezogabine on motor neuron activity in patients. The objective is to determine if ezogabine affects neurophysiological measures of upper and lower motor neuron excitability in ALS patients. The study is recruiting patients sponsored by Brian Wainger in collaboration with ALS Association, GlaxoSmithKline, Harvard University and the Massachusetts General Hospital (Clinicaltrial.gov NCT02450552).

5.6 Memantine. The glutamate antagonist memantine, marketed for advanced stages of Alzheimer's disease, was clinically assayed in combination with riluzole in a phase II/III, 12-months, double-blind, single- centre, randomized, parallel (1:1), clinical trial showing that this drug combination is well tolerated and safe in ALS patients, and although the primary endpoint was not achieved, the results suggested a slow ALS disease progression [53]. Moreover, this trial also showed a correlation between biomarkers in CSF and the rate of disease progression [54]. Currently, a new study is proposed, sponsored by the University of Kansas Medical Center (USA), to test a higher dose of memantine, $20 \mathrm{mg} \mathrm{BID}$, in a double blind, placebo controlled, 
randomized trial of 90 patients with ALS. The main goal is to determine if the combination therapy of memantine with riluzole can slow disease progression compared to treatment with riluzole alone (Clinicaltrial.gov NCT02118727). R esults, expected for October 2019, will set the groundwork for conducting a larger phase III trial.

5.7 Rasagiline, a monoamine oxidase B inhibitor approved for the treatment of Parkinson's disease, slowed disease progression in the SOD1 mouse [55], and in a small number of patients with ALS treated in Canada and USA ( Clinicaltrial.gov NCT01232738) [56]. In August 2016, a robust Phase II study with rasagiline was completed. The study was performed in Ulm University with the primary objective to investigate the survival time in ALS-Patients (Clinicaltrial.gov NCT01879241). The study will try to compare the placebo with $1 \mathrm{mg} / \mathrm{d}$ rasagiline as an add-on therapy to $100 \mathrm{mg}$ riluzole in ALS in 250 enrolled patients. The final data will be available in the next months.

5.8 Cistanche total glycosides. Additionally, a $\mathrm{n}$ herb extract used in traditional Chinese medicine is also in clinical trials for ALS. Cistanche total glycosides (CTG) is an approved drug in China that has protective effects. It acts as an anti-apoptosis agent by activating several protective pathways, stimulates neuronal differentiation of adult neural stem cells in the brain, and improves long-term recovery [57]. Moreover, an openlabel, non-placebo-controlled study on CTG capsules ( Memoregain ${ }^{\circledR}$ ) demonstrate d that the drug has potential to be a treatment option for mild to moderate $A D$, and all adverse reactions were mild [58]. CTG is a highly attractive candidate for the treatment of neurodegenerative conditions such as ALS and a clinical trial to assess its clinical response is being sponsored by University of Pekin (Clinicaltrial.gov NCT00753571). However, data is not available at the moment.

5.9 Masitinib, is a tyrosine-kinase inhibitor marketed by AB Science under the name Kinavet to treat a certain cancer in dogs. This kinase inhibitor blocks mast cellmediated degranulation, and the release of proinflammatory cytokines. Masitinib aims to slow progression of ALS by reducing inflammation. Recently, the decreased of aberrant glial cells, microgliosis and the motor neuron pathology in the degenerating spinal cord of SOD-1 mice after oral administration of this drug have been reported, providing a strong biological rationale for its use to control neuroinflammation in ALS [59]. A clinical trial aim ing to compare the efficacy and safety of masitinib in combination with riluzole in the treatment of patients suffering from ALS (Clinicaltrial.gov NCT02588677) is ongoing and final results are expected by the end of 
the year. However, the interim analysis done when the $50 \%(\mathrm{~N}=191)$ of the people with ALS enrolled completed the trial has shown that the study has met its primary endpoint, which was defined as a change in ALSFRS-R score. It takes 48 weeks for each person with ALS to complete the trial. While this intermediate report is encouraging, the data from all those in the trial $(\mathrm{N}=190)$ should be considered when the whole study is completed.

5.10 Recently finished clinical trials. It is worthwhile to mention the recent results obtained in the clinical development of methylcobalamine and edaravone that have finished very recently.

5.10.1 Methylcobalamin. The protective effect on cultured cortical neurons against glutamate-induced cytotoxicity shown by methylcobalamin (E0302), a physiologically equivalent to vitamin B ${ }_{12}$ [60], was the support for a clinical trial in ALS patients sponsored by Eisai Co., Ltd. (Japan) (Clinicaltrial.gov NCT00444613) recently finished. The aim of this study was to investigate the efficacy and confirm the safety of ultra -high dose, 50 to 100 times the approved dose, of methylcobalamin in ALS patients. The analysis of changes in scores of survival rate and functional rating scale, demonstrated for the first time that the studied treatment can significantly prolong survival and retard progression in ALS if administered early [61]. Additionally, after high-dose treatment of wobbler mouse motor neuron disease with methylcobalamin (E0302), it was observed a retard in the progression of motor symptoms and neuropathological changes [62]. However, in March 2016 the Japanesse regulatory drug agency ( PMDA) decided that the application of mecobalamin as a treatment for ALS, was not sufficient for approval and the company subsequently withdrew it. Currently, Eisai is reconsidering future development strateg ies for mecobalamine. Meanwhile, MD1003 a pharmaceutical formulation of high-dose biotin, the water soluble type of vitamin B has recently started clinical development for ALS (E udraCT Number: 2015-005810-31 ). The trial is sponsored by MedDay Pharmaceuticals and the main goal is to explore the safety of biotin administration to ALS patients.

\subsubsection{Edaravone (Radicut, $\mathrm{MCl}-186$ ) is a free radical scavenger and a potent} antioxidant, marketed only in Japan by Mitsubishi Tanabe Pharma to aid the neurological recovery following acute brain ischemia and subsequent cerebral infarction [63]. Based on this neuroprotective activity and on the ability to slow motor decline in the SOD1 transgenic mice [64], Mitsubishi Tanabe started clinical trials to evaluate the efficacy and safety of Edaravone in ALS patients. In a phase II clinical trial of edaravone, in a sub-group of people with ALS in Japan, researchers found a statistically significant improvement in the ALS Function Rating Scale-Revise. In 2015, 
Edaravone was approved as a new therapeutic option for ALS in Japan and South Korea. In the same year, the FDA and the European Commission granted Orphan Drug Designation for edaravone and in June 2016, the FDA has accepted the application of edaravone for ALS treatment. A decision on the application is anticipated for June 2017. Hopefully, this promising drug will be effective at slowing the progression of ALS and providing some disease reversal, particularly when taken by those who have had the disease for less than three years.

\section{Here, Figure 2}

\section{New drugs for ALS under clinical development}

The urgent need of finding a cure for ALS has pressured different academic and private laboratories to start drug discovery programs directed to modulate this fatal pathology despite its unknown etiology or the lack of good cellular or animal models that mimic the disease $[65,66]$. As a result, currently there are several new investigational drugs in clinical trials for ALS (Figure 3).

6.1 Tirasemtiv. Although the regulation of muscle contraction by the troponin complex is well known [67], only in the last few years it was discovered that $t$ roponin activation may provide a new therapeutic approach to improve physical activity in diseases where neuromuscular function is compromised [68]. In that way, the small molecule CK2017357 also known as Tirasemtiv, a fast-skeletal-troponin activator, is able to increase muscle strength and performance in mice modulating the rate of calcium release from troponin $C$ [69]. Moreover, and after showing to be safe and tolerable in ALS patients [70], Tirasemtiv has shown the potential to amplify the skeletal muscle response in humans [71]. Recently, it has received the orphan drug designation and fast-track status by the FDA and the EMA for the potential treatment of people with ALS (ORPHA299528). Based on this, the biopharmaceutical Cytokinetics started a large and international phase III study called VITALITY-ALS (Clinicaltrial.gov NCT02496767). The enrollment ended in August 2016 and results are expected for the second half of 2017. A second clinical study, VIGOR-ALS (Clinicaltrial.gov NCT02936635) , has recently started as an extension of VITALITY-ALS to include ALS patients who have completed th is previous study. The main goal of this clinical trial is to study the longterm safety and tolerability among the patients. Estimated study completion will be in October 2019 and data evaluation may then provide a therapy to combat ALS.

6.2 Arimoclomol, a small molecule discovered initially by Hungarian researchers as a drug candidate to treat insulin resistance and diabetic complications [72], has recently 
shown to reduce protein aggregates levels in motor nerves. This new investigational drug candidate is able to increase the expression of chaperons Hsp70 and Hsp90 which help newly synthesized proteins fold properly [73]. Arimoclomol has also shown beneficial effects in muscle denervation in the SOD transgenic ALS mice [74], and is being tested in a Phase II/III study to determine tolerability and efficacy in subjects with SOD1 positive familial ALS sponsored by the University of Miami (USA) (Clinicaltrial.gov NCT00706147). Previously, arimoclomol showed to be well tolerated in ALS patients [75]. Results from the ongoing study are expected by the end of the year and will indicate if arimoclomol could become a disease modifiying drug for this familial subgroup of patients.

6.3 RNS60. This novel therapeutic is an electrokinetically altered aqueous fluid composed of $0.9 \%$ saline containing charge-stabilized oxygen nanobubble-based structures. Chemically, RNS60 contains water, sodium chloride, and $55 \pm 5 p p m$ oxygen. Despite the absence of active pharmaceutical ingredients, RNS60 has proven to be antiinflammatory and neuroprotective in different models [76-78], being proposed as a new therapeutic option for neuroinflammatory and neurodegenerative disorders [79]. Furthermore, RNS60 has shown some benefit in myelin maintenance and repair [80]. Sponsored by Revalesio, a Phase I clinical study to determine safety and tolerability in ALS patients has been initiated with RNS60 administered by intravenous and inhalation routes (Clinicaltrial.gov NCT02525471). The study is recruiting ALS volunteers and the completion of the study is estimated by the end of 2017 .

6.4 Cu(II)ATSM. One of the causes of some familiar forms of ALS are mutations in the metallo-protein Cu/Zn-superoxide dismutase (SOD1) and over-expression of mutant SOD1 in mice induces ALS symptoms, being the most widely used model for this disease. The aberrant persistence of SOD1 in an intermediate metal-deficient state may contribute to the pathogenic role of this protein in ALS [81]. The PET-imaging agent $\mathrm{Cu}$ (II)ATSM (diacetyl-bis(4-methylthiosemicarbazonato)copperlI), is known to deliver copper into the CNS within minutes , and was used to restore the copper homeostasis in SOD1 transgenic mice finding s ignificant improvements in the locomotor function and survival $[82,83]$. Collaborative Medicinal Development Pty Limited (US/Australian) initiated the clinical development of Cu(II)ATSM with a multicenter, open-label, phase I study of Cu(II)ATSM administered orally to patients with ALS/motor neuron disease (Clinicaltrial.gov NCT02870634). A copper deficiency in spinal cord of ALS patients similar to SOD1 transgenic mice has recently been shown [84], the use of $\mathrm{Cu}(\mathrm{II}) \mathrm{ATSM}$ may attenuate disease symptoms and prolong survival in sporadic ALS patients as it was observed in SOD1 animal models. 
6.5 NP001. Based on the relationship between ALS progression and neuroinflammation [85], NP001, a small heterocyclic molecule regulator of inflammatory macrophages and monocytes, was included in a phase I study in patients with ALS showing to be safe and tolerable [86]. Afterwards, a Phase II to assess preliminary efficacy of NP001 in ALS patients was conducted [87], presenting a decrease of disease progression in a small subset of patients which motivated Neuraltus Pharmaceuticals (USA) to start a second Phase II clinical study to confirm this data (Clinicaltrial.gov NCT02794857). The recruitment is currently open.

6.6 EPI-589.The small molecule EPI-589, also named as (R)-troloxamide quinone, has started clinical development. Although there is no data available about the efficacy of this antioxidant drug in ALS animal models , Edison Pharmaceutical initiated a Phase IIA safety and biomarker study of EPI-589 in ALS patients. As the new drug candidate acts through a redox-based mechanism, the secondary outcome of the study will be the potential impact of the compound on the levels of glutathione in blood samples from participants (Clinicaltrial.gov NCT02460679).

6.7 GDC-0134. Finally, GDC-0134 is an inhibitor of Dual Leucine Zipper Kinase (DLK) being developed by Genentech. A clinical trial phase I is currently recruiting participants in a single ascending-dose study to determine the safety, tolerability and some pharmacokinetic parameters. DLK regulates neuronal regeneration and it was recently shown that its inhibition promotes neuroprotection, preventing axon degeneration [88], which could be of great benefit to treat ALS patients.

$$
\text { Here, Figure } 3
$$

\section{Conclusions}

Finding a cure for ALS is one of the great est challenges for those working in central nervous system drug discovery. Not only for the severity of the disease and the great social need, but also for the lack of validated targets and animal models. However, thanks to recent public and private research and development effort $\mathrm{s}$, we have currently several clinical trials ongoing to fight against ALS.

Some studies are focused on the development of imaging-agents that will allow for a better diagnostic and disease follow-up in the next future, being the development of MRI/PET agents the most advanced one. Other clinical trials are focused in cell therapy strategies. There are several studies ongoing , but up to date there is a lack of highquality evidence to guide practice on the use of cell-based therapy to treat ALS [89]. Important key points such as the determination of the appropriate cell source, 
phenotype, dose and route of delivery must be determine

d in future research.

Furthermore, other therapeutic approaches such as plasma exchange with Albutein® $5 \%$ in patients with ALS are ongoing (Clinicaltrial.gov NCT02872142). The main goal of Griffols who sponsors the trial is to evaluate disease progression, forced vital capacity and the safety and tolerability of plasma exchange on ALS patients.

Finally, more than a dozen new drugs are now in clinical investigation for ALS therapy, offering some hope for patients in the near future. Although the great number of drugs currently in clinical trials have the main goal of protecting the motor neuron and modifying the course of the disease, some compounds as tirasemtiv, for example, have been develop only to improve some of the most disabling clinical symptoms for the patients such as muscle strength. Nevertheless, it is important to mention the orphan medicinal product designation granted by the FDA to ibudilast and endaravone, because somehow recognize s the potential efficacy in neuroprotection of these drugs and will decrease the development time to reach the market. In fact, enderavone has been already approved in Japan for the treatment of ALS and the corresponding application has just been submitted to the FDA. Most likely, edaravone together with masitinib, if the second part of the ongoing study displays the same behavior than the first one, will be the drug candidates nearer to the market.

\section{Expert Opinion}

ALS is a fatal and devastating neurodegenerative disease for which no treatment exists. This terrible deficiency may be due to a number of factors.

The first historical one may be found in the number of patients affected by the disease. ALS is a rare disease and, based exclusively in economic criteria , little research has been done by pharma companies until the last years/decades in th is kind of pathologies. In fact, it has been the public claims coming from patient associations that have recently impacted favorably on investment decisions and research on rare diseases is currently one of the preferred fields for many companies. ALS patient 's associations are very active and believe in research as the only way to find a cure , investing resources and leading an important opinion to guide investments coming from public and private sectors.

A second important point is the lack of good animal models able to mimic the disease. Since the ninety 's decade no models were available, and after , different transgenic mice were developed based only in different mutations of SOD-1. Finding some signs of efficacy in those mice after treatment with different molecules was not significantly difficult. $\mathrm{H}$ owever, the translation of the preclinical results to the clinic has been unsuccessful every time. Currently, after some years of basic and applied research, it is 
known that SOD-1 mutations are present only in less than $10 \%$ of familiar ALS cases which represents a small fraction of the overall disease. Differ ent strategies are being follow ed now to improve translational research success [7], being personalized medicine a new opportunity for genetic patients. Furthermore, as the knowledge of the pathobiology of ALS advances, investigators are focusing on concepts that had not been examined previously and new animal models are being developed to provide innovative future possibilities for drug discovery [90]. In that sense, is relevant the recently acquired knowledge regarding the nuclear TAR-DNA binding protein 43 (TDP-43) and its key role in the pathology of ALS. Different animal models have been recently developed considering several strategies to upregulate this protein with the aim to emulate the disease, but without compromising the animal 's viability [91]. Directing the differentiation of human induced pluripotent stem cells into motor neurons as a way to develop new models of ALS constitutes another important alternative to be considered [92]. Although several technical challenges may still need to be solve $d$, having the disease-in-a-dish will enhance the validation of new drugs that may be effective for ALS.

A third important challenge to be considered is that only now researchers are beginning to understand the biochemical and genetic causes behind ALS pathology. This new knowledge is being incorporated in the new drugs or therapies under development for clinically indistinguishable forms of ALS. This disease may occur as sporadic disorder in the absence of known mutation, or can be initiated by genetic mutations. In the last case, mutations in four genes that are chromosome 9 open reading frame 72 (C9ORF72), Cu/Zn superoxide dismutase (SOD1), fused in sarcoma/translocated in liposarcoma (FUS/TLS), and TDP-43, cause a bout two-third of these familial cases. New methodologies, as the fine regulators of genetic networks Micro RNAs or miRNAs start to emerge as a personalized medicine strategy [93].

Despite all these drawbacks, the new interventions under research will have important consequences for the direction of ALS treatment. These studies will surely add knowledge to the overall understanding of ALS which will produce a better design and/or selection of drug candidates. Drug repositioning is currently playing an important role to bring new therapeutics for ALS patients. Different new molecules are in the last steps of clinical development with acceptable preliminary results and some of them have been recognized as orphan drugs by the regulatory agencies. The expectation aroused on masitinib and edaravone is worth mentioning. The last one has now the approval for use in Japan and the clinical practice will provide the final piece for the battle against ALS. Both compounds are neuroprotectants and may have a profound 
impact in disease progression. Moreover, the recently started clinical phase I for the small molecule targeting DLK opens new avenues for specific drug development for ALS. All of these factors, joined to new criteria for clinical trial designs [8], leads us to believe that future research will find the best approach to prevent or reverse the neurological deficit in ALS, and prolong survival rates in this debilitating and fatal condition.

\section{Acknowledgements}

This work was financially supported by MINECO (grant no. SAF2012-37979-C03-01 to A.M. and IJCl-2014-20767 to V.P.)

\section{References}

$(\bullet=$ of importance, $\bullet=$ of considerable importance)

1. Talbott EO, Malek AM, Lacomis D. The epidemiology of amyotrophic lateral sclerosis. Handb Clin Neurol 2016;138:225-38

2. Zarei S, Carr K, Reiley L, et al. A comprehensive review of amyotrophic lateral sclerosis. Surg Neurol Int 2015;6:171

3. Zufiria M, Gil-Bea FJ, Fernandez-Torron R, et al. ALS: A bucket of genes, environment, metabolism and unknown ingredients. Prog Neurobiol 2016;142:104-29

4. Mathis $S$, Couratier $P$, Julian A, et al. Management and therapeutic perspectives in amyotrophic lateral sclerosis. Expert Rev Neurother 2016:1-14

5. Miller RG, Mitchell JD, Moore DH. Riluzole for amyotrophic lateral sclerosis (ALS)/motor neuron disease (MND). Cochrane Database Syst Rev 2012:Cd001447 6. Cheramy A, Barbeito L, Godeheu G, et al. Riluzole inhibits the release of glutamate in the caudate nucleus of the cat in vivo. Neurosci Lett 1992;147:209-12 7. Ittner LM, Halliday GM, Kril JJ, et al. FTD and ALS--translating mouse studies into clinical trials. Nature reviews Neurology 2015;11:360-6 -• comprehensible review to undertand the lack of effective drugs for ALS 8. Nicholson KA, Cudkowicz ME, Berry JD. Clinical Trial Designs in Amyotrophic Lateral Sclerosis: Does One Design Fit All? Neurotherapeutics 2015;12:376-83

9. Harikrishnareddy D, Misra S, Upadhyay S, et al. Roots to start research in amyotrophic lateral sclerosis: molecular pathways and novel therapeutics for future. Rev Neurosci 2015;26:161-81

- This paper summarized the recent knowledge about the molecular pathology in ALS 10. Kumar V, Islam A, Hassan MI, et al. Therapeutic progress in amyotrophic lateral sclerosis-beginning to learning. Eur J Med Chem 2016;121:903-17

11. Mitchell JD, Callagher P, Gardham J, et al. Timelines in the diagnostic evaluation of people with suspected amyotrophic lateral sclerosis (ALS)/motor neuron 
disease (MND)--a 20-year review: can we do better? Amyotroph Lateral Scler 2010;11:537-41

12. Biomarkers and surrogate endpoints: preferred definitions and conceptual framework. Clin Pharmacol Ther 2001;69:89-95

13. Benatar M, Boylan K, Jeromin A, et al. ALS biomarkers for therapy development: State of the field and future directions. Muscle Nerve 2016;53:169-82 14. Fan Z, Calsolaro V, Atkinson RA, et al. Flutriciclamide (18F-GE180) PET: Firstin-Human PET Study of Novel Third-Generation In Vivo Marker of Human Translocator Protein. J Nucl Med 2016;57:1753-59

15. Kim T, Pae AN. Translocator protein (TSPO) ligands for the diagnosis or treatment of neurodegenerative diseases: a patent review (2010 - 2015; part 2). Expert Opin Ther Pat 2016;26:1353-66

16. Liu B, Le KX, Park MA, et al. In Vivo Detection of Age- and Disease-Related Increases in Neuroinflammation by 18F-GE180 TSPO MicroPET Imaging in Wild-Type and Alzheimer's Transgenic Mice. J Neurosci 2015;35:15716-30

17. Grossman M, Elman L, McCluskey L, et al. Phosphorylated tau as a candidate biomarker for amyotrophic lateral sclerosis. JAMA Neurol 2014;71:442-8

18. Harada R, Okamura N, Furumoto $S$, et al. Characteristics of Tau and Its Ligands in PET Imaging. Biomolecules 2016;6:7

19. Eisele $\mathrm{P}$, Konstandin $\mathrm{S}$, Griebe $\mathrm{M}$, et al. Heterogeneity of acute multiple sclerosis lesions on sodium (23Na) MRI. Mult Scler 2016;22:1040-7

20. Mellon EA, Pilkinton DT, Clark CM, et al. Sodium MR Imaging Detection of Mild Alzheimer Disease: Preliminary Study. AJNR American journal of neuroradiology 2009;30:978-84

21. Reetz K, Romanzetti S, Dogan I, et al. Increased brain tissue sodium concentration in Huntington's Disease - a sodium imaging study at $4 \mathrm{~T}$. Neuroimage 2012;63:517-24

22. Aebischer J, Moumen A, Sazdovitch V, et al. Elevated levels of IFNgamma and LIGHT in the spinal cord of patients with sporadic amyotrophic lateral sclerosis. Eur $\mathrm{J}$ Neurol 2012;19:752-9, e45-6

23. Liu J, Gao L, Zang D. Elevated Levels of IFN-gamma in CSF and Serum of Patients with Amyotrophic Lateral Sclerosis. PLoS One 2015;10:e0136937

24. Srivastava AK, Bulte JW. Seeing stem cells at work in vivo. Stem Cell Rev 2014;10:127-44

25. Mao Z, Zhang S, Chen H. Stem cell therapy for amyotrophic lateral sclerosis. Cell Regeneration 2015;4:11

- Risks and benefits of stem cell therapy for ALS are discussed in this paper. 
26. Ferrero I, Mazzini L, Rustichelli D, et al. Bone marrow mesenchymal stem cells from healthy donors and sporadic amyotrophic lateral sclerosis patients. Cell Transplant 2008;17:255-66

27. Blanquer M, Moraleda JM, Iniesta F, et al. Neurotrophic Bone Marrow Cellular Nests Prevent Spinal Motoneuron Degeneration in Amyotrophic Lateral Sclerosis Patients: A Pilot Safety Study. STEM CELLS 2012;30:1277-85

28. Deda $\mathrm{H}$, Inci MC, Kurekci AE, et al. Treatment of amyotrophic lateral sclerosis patients by autologous bone marrow-derived hematopoietic stem cell transplantation: a 1-year follow-up. Cytotherapy 2009;11:18-25

29. Mazzini L, Fagioli F, Boccaletti R, et al. Stem cell therapy in amyotrophic lateral sclerosis: a methodological approach in humans. Amyotroph Lateral Scler Other Motor Neuron Disord 2003;4

30. Oh KW, Moon C, Kim HY, et al. Phase I trial of repeated intrathecal autologous bone marrow-derived mesenchymal stromal cells in amyotrophic lateral sclerosis. Stem Cells Transl Med 2015;4:590-7

31. Lepore AC, O'Donnell J, Kim AS, et al. Human glial-restricted progenitor transplantation into cervical spinal cord of the SOD1 mouse model of ALS. PLoS One 2011;6:e25968

32. Atassi N, Beghi E, Blanquer M, et al. Intraspinal stem cell transplantation for amyotrophic lateral sclerosis: Ready for efficacy clinical trials? Cytotherapy 2016;18:1471-75

33. Petrou $P$, Gothelf $Y$, Argov Z, et al. Safety and Clinical Effects of Mesenchymal Stem Cells Secreting Neurotrophic Factor Transplantation in Patients With Amyotrophic Lateral Sclerosis: Results of Phase 1/2 and 2a Clinical Trials. JAMA Neurol 2016;73:337-44

34. Smith RA, Miller TM, Yamanaka K, et al. Antisense oligonucleotide therapy for neurodegenerative disease. J Clin Invest 2006;116:2290-6

35. Miller TM, Pestronk A, David W, et al. An antisense oligonucleotide against SOD1 delivered intrathecally for patients with SOD1 familial amyotrophic lateral sclerosis: a phase 1, randomised, first-in-man study. Lancet Neurol 2013;12:435-42 36. Oldfield V, Dhillon S, Plosker GL. Tocilizumab: a review of its use in the management of rheumatoid arthritis. Drugs 2009;69:609-32

37. Teng FY, Tang BL. Nogo-A and Nogo-66 receptor in amyotrophic lateral sclerosis. J Cell Mol Med 2008;12:1199-204

38. Bros-Facer V, Krull D, Taylor A, et al. Treatment with an antibody directed against Nogo-A delays disease progression in the SOD1G93A mouse model of Amyotrophic lateral sclerosis. Hum Mol Genet 2014;23:4187-200 
39. Meininger V, Pradat PF, Corse A, et al. Safety, pharmacokinetic, and functional effects of the nogo-a monoclonal antibody in amyotrophic lateral sclerosis: a randomized, first-in-human clinical trial. PLoS One 2014;9:e97803

40. McCormick AL, Brown RH, Jr., Cudkowicz ME, et al. Quantification of reverse transcriptase in ALS and elimination of a novel retroviral candidate. Neurology 2008;70:278-83

41. Douville R, Liu J, Rothstein J, et al. Identification of active loci of a human endogenous retrovirus in neurons of patients with amyotrophic lateral sclerosis. Ann Neurol 2011;69:141-51

42. Christensen T. Human endogenous retroviruses in neurologic disease. APMIS 2016;124:116-26

43. Li W, Lee MH, Henderson L, et al. Human endogenous retrovirus-K contributes to motor neuron disease. Sci Transl Med 2015;7:307ra153

44. Mizuno T, Kurotani T, Komatsu Y, et al. Neuroprotective role of phosphodiesterase inhibitor ibudilast on neuronal cell death induced by activated microglia. Neuropharmacology 2004;46:404-11

45. Goodman A. Tamoxifen, a cancer therapy, explored for ALS. Neurology Today 2005;5:22-26

46. Zou W, Fang C, Ji X, et al. Estrogen Receptor (ER)-alpha36 Is Involved in Estrogen- and Tamoxifen-Induced Neuroprotective Effects in Ischemic Stroke Models. PLoS One 2015;10:e0140660

47. $\mathrm{Hu} \mathrm{JH}$, Zhang $\mathrm{H}$, Wagey $\mathrm{R}$, et al. Protein kinase and protein phosphatase expression in amyotrophic lateral sclerosis spinal cord. J Neurochem 2003;85:432-42 48. Wang IF, Guo BS, Liu YC, et al. Autophagy activators rescue and alleviate pathogenesis of a mouse model with proteinopathies of the TAR DNA-binding protein 43. Proc Natl Acad Sci U S A 2012;109:15024-9

49. Noto $Y$, Shibuya K, Vucic $S$, et al. Novel therapies in development that inhibit motor neuron hyperexcitability in amyotrophic lateral sclerosis. Expert Rev Neurother 2016;16:1147-54

50. Weiss MD, Macklin EA, Simmons Z, et al. A randomized trial of mexiletine in ALS: Safety and effects on muscle cramps and progression. Neurology 2016;86:147481

51. Rudzinski LA, Velez-Ruiz NJ, Gedzelman ER, et al. New antiepileptic drugs: focus on ezogabine, clobazam, and perampanel. J Investig Med 2016;64:1087-101 52. Wainger BJ, Kiskinis E, Mellin C, et al. Intrinsic membrane hyperexcitability of amyotrophic lateral sclerosis patient-derived motor neurons. Cell Rep 2014;7:1-11

53. de Carvalho M, Pinto S, Costa J, et al. A randomized, placebo-controlled trial of 
memantine for functional disability in amyotrophic lateral sclerosis. Amyotroph Lateral Scler 2010;11:456-60

54. Levine TD, Bowser R, Hank N, et al. A pilot trial of memantine and riluzole in ALS: correlation to CSF biomarkers. Amyotroph Lateral Scler 2010;11:514-9

55. Waibel S, Reuter A, Malessa S, et al. Rasagiline alone and in combination with riluzole prolongs survival in an ALS mouse model. J Neurol 2004;251:1080-4

56. Macchi $Z$, Wang $Y$, Moore D, et al. A multi-center screening trial of rasagiline in patients with amyotrophic lateral sclerosis: Possible mitochondrial biomarker target engagement. Amyotroph Lateral Scler Frontotemporal Degener 2015;16:345-52 57. Li Z, Lin H, Gu L, et al. Herba Cistanche (Rou Cong-Rong): One of the Best Pharmaceutical Gifts of Traditional Chinese Medicine. Front Pharmacol 2016;7:41 58. Guo Q, Zhou Y, Wang CJ, et al. An open-label, nonplacebo-controlled study on Cistanche tubulosa glycoside capsules (Memoregain $((R))$ ) for treating moderate Alzheimer's Disease. Am J Alzheimers Dis Other Demen 2013;28:363-70

59. Trias E, Ibarburu S, Barreto-Nunez R, et al. Post-paralysis tyrosine kinase inhibition with masitinib abrogates neuroinflammation and slows disease progression in inherited amyotrophic lateral sclerosis. J Neuroinflammation 2016;13:177

60. Izumi Y, Kaji R. [Clinical trials of ultra-high-dose methylcobalamin in ALS]. Brain Nerve 2007;59:1141-7

61. Kaji R, Kuzuhara S, Iwasaki Y, et al. Ultra-high dose methylcobalamin (E0302) prolongs survival of ALS: Report of 7 years' randomised double-blind, phase 3 clinical trial (ClinicalTrials.gov NCT00444613) (P7.060). Neurology 2015;84

62. Ikeda K, Iwasaki Y, Kaji R. Neuroprotective effect of ultra-high dose methylcobalamin in wobbler mouse model of amyotrophic lateral sclerosis. J Neurol Sci 2015;354:70-4

63. Yoshida $\mathrm{H}$, Yanai $\mathrm{H}, \mathrm{Namiki}$ Y, et al. Neuroprotective effects of edaravone: a novel free radical scavenger in cerebrovascular injury. CNS Drug Rev 2006;12:9-20 - The molecular basis to use endaravone for ALS therapy is described in this paper. 64. Ito $\mathrm{H}$, Wate $\mathrm{R}$, Zhang J, et al. Treatment with edaravone, initiated at symptom onset, slows motor decline and decreases SOD1 deposition in ALS mice. Exp Neurol 2008;213:448-55

65. DeLoach A, Cozart M, Kiaei A, et al. A retrospective review of the progress in amyotrophic lateral sclerosis drug discovery over the last decade and a look at the latest strategies. Expert Opin Drug Discov 2015;10:1099-118

-• A complementary paper to acquire a complete view of current pipeline in ALS therapy research

66. Bucchia M, Ramirez A, Parente V, et al. Therapeutic development in 
amyotrophic lateral sclerosis. Clin Ther 2015;37:668-80

67. Farah CS, Reinach FC. The troponin complex and regulation of muscle contraction. Faseb j 1995;9:755-67

68. Russell AJ, Hartman JJ, Hinken AC, et al. Activation of fast skeletal muscle troponin as a potential therapeutic approach for treating neuromuscular diseases. Nat Med 2012;18:452-5

69. Hwee DT, Kennedy A, Ryans J, et al. Fast skeletal muscle troponin activator tirasemtiv increases muscle function and performance in the B6SJL-SOD1G93A ALS mouse model. PLoS One 2014;9:e96921

70. Shefner JM, Watson ML, Meng L, et al. A study to evaluate safety and tolerability of repeated doses of tirasemtiv in patients with amyotrophic lateral sclerosis. Amyotroph Lateral Scler Frontotemporal Degener 2013;14:574-81

71. Hansen R, Saikali KG, Chou W, et al. Tirasemtiv amplifies skeletal muscle response to nerve activation in humans. Muscle Nerve 2014;50:925-31

72. Kurthy M, Mogyorosi T, Nagy K, et al. Effect of BRX-220 against peripheral neuropathy and insulin resistance in diabetic rat models. Ann N Y Acad Sci 2002;967:482-9

73. Kalmar B, Lu CH, Greensmith L. The role of heat shock proteins in Amyotrophic Lateral Sclerosis: The therapeutic potential of Arimoclomol. Pharmacol Ther 2014;141:40-54

74. Kalmar B, Edet-Amana E, Greensmith L. Treatment with a coinducer of the heat shock response delays muscle denervation in the SOD1-G93A mouse model of amyotrophic lateral sclerosis. Amyotroph Lateral Scler 2012;13:378-92

75. Cudkowicz ME, Shefner JM, Simpson E, et al. Arimoclomol at dosages up to $300 \mathrm{mg} /$ day is well tolerated and safe in amyotrophic lateral sclerosis. Muscle Nerve 2008;38:837-44

76. Khasnavis S, Jana A, Roy A, et al. Suppression of nuclear factor-kappaB activation and inflammation in microglia by physically modified saline. J Biol Chem 2012;287:29529-42

77. Khasnavis S, Roy A, Ghosh S, et al. Protection of dopaminergic neurons in a mouse model of Parkinson's disease by a physically-modified saline containing chargestabilized nanobubbles. J Neuroimmune Pharmacol 2014;9:218-32

78. Modi KK, Jana A, Ghosh S, et al. A physically-modified saline suppresses neuronal apoptosis, attenuates tau phosphorylation and protects memory in an animal model of Alzheimer's disease. PLoS One 2014;9:e103606

79. Choi S, Yu E, Kim DS, et al. RNS60, a charge-stabilized nanostructure saline alters Xenopus Laevis oocyte biophysical membrane properties by enhancing 
mitochondrial ATP production. Physiol Rep 2015;3

80. Rao VT, Khan D, Jones RG, et al. Potential Benefit of the Charge-Stabilized Nanostructure Saline RNS60 for Myelin Maintenance and Repair. Sci Rep 2016;6:30020

81. Hilton JB, White AR, Crouch PJ. Metal-deficient SOD1 in amyotrophic lateral sclerosis. J Mol Med (Berl) 2015;93:481-7

82. McAllum EJ, Lim NK, Hickey JL, et al. Therapeutic effects of Cull(atsm) in the SOD1-G37R mouse model of amyotrophic lateral sclerosis. Amyotroph Lateral Scler Frontotemporal Degener 2013;14:586-90

83. Williams JR, Trias E, Beilby PR, et al. Copper delivery to the CNS by CuATSM effectively treats motor neuron disease in SOD(G93A) mice co-expressing the CopperChaperone-for-SOD. Neurobiol Dis 2016;89:1-9

84. Hilton JB, White AR, Crouch PJ. Endogenous $\mathrm{Cu}$ in the central nervous system fails to satiate the elevated requirement for $\mathrm{Cu}$ in a mutant SOD1 mouse model of ALS. Metallomics 2016;8:1002-11

85. Philips T, Robberecht W. Neuroinflammation in amyotrophic lateral sclerosis: role of glial activation in motor neuron disease. Lancet Neurol 2011;10:253-63

- The role of glial activation in ALS is clearly stated in this paper

86. Miller RG, Zhang R, Block $\mathrm{G}$, et al. NP001 regulation of macrophage activation markers in ALS: a phase I clinical and biomarker study. Amyotroph Lateral Scler Frontotemporal Degener 2014;15:601-9

87. Miller RG, Block G, Katz JS, et al. Randomized phase 2 trial of NP001-a novel immune regulator: Safety and early efficacy in ALS. Neurol Neuroimmunol Neuroinflamm 2015;2:e100

88. Patel S, Cohen F, Dean BJ, et al. Discovery of Dual Leucine Zipper Kinase (DLK, MAP3K12) Inhibitors with Activity in Neurodegeneration Models. Journal of Medicinal Chemistry 2015;58:401-18

89. Abdul Wahid SF, Law ZK, Ismail NA, et al. Cell-based therapies for amyotrophic lateral sclerosis/motor neuron disease. Cochrane Database Syst Rev 2016;11:Cd011742

90. Philips T, Rothstein JD. Rodent Models of Amyotrophic Lateral Sclerosis. Curr Protoc Pharmacol 2015;69:5.67.1-21

91. Liu YC, Chiang PM, Tsai KJ. Disease animal models of TDP-43 proteinopathy and their pre-clinical applications. Int J Mol Sci 2013;14:20079-111

92. Sances S, Bruijn LI, Chandran S, et al. Modeling ALS with motor neurons derived from human induced pluripotent stem cells. Nat Neurosci 2016;19:542-53 •• Future models to screen new drugs using different human cells derived from patients 
are clearly described in the paper

93. Volonte C, Apolloni S, Parisi C. MicroRNAs: newcomers into the ALS picture. CNS Neurol Disord Drug Targets 2015;14:194-207 
Table 1: Ongoing Clinical trials for ALS aimed to alleviate some of the disease symptoms

\begin{tabular}{|c|c|c|c|c|}
\hline No & Title & Goal & Sponsor & $\begin{array}{l}\text { Estimated Study } \\
\text { Completion Date }\end{array}$ \\
\hline NCT02710162 & $\begin{array}{l}\text { Accurate Screening } \\
\text { Tools for Dysphagia } \\
\text { in ALS }\end{array}$ & $\begin{array}{l}\text { To evaluate the } \\
\text { discriminant ability of } \\
\text { several non-invasive } \\
\text { screening tools at } \\
\text { detecting swallowing } \\
\text { impairment in } \\
\text { individuals with ALS. }\end{array}$ & $\begin{array}{l}\text { University } \\
\text { of Florida, } \\
\text { USA }\end{array}$ & March 2017 \\
\hline NCT02969759 & $\begin{array}{l}\text { Bioenergetics and } \\
\text { Protein Metabolism } \\
\text { in Sporadic ALS }\end{array}$ & $\begin{array}{l}\text { To precise the } \\
\text { implication of energy } \\
\text { and protein } \\
\text { metabolism in the } \\
\text { sporadic forms of ALS. }\end{array}$ & $\begin{array}{l}\text { University } \\
\text { Hospital, } \\
\text { Angers, } \\
\text { France }\end{array}$ & November 2019 \\
\hline NCT02710110 & $\begin{array}{l}\text { Respiratory } \\
\text { Strength Training in } \\
\text { Persons With ALS }\end{array}$ & $\begin{array}{l}\text { To determine the } \\
\text { impact of respiratory } \\
\text { strength training on } \\
\text { breathing, airway } \\
\text { protection and } \\
\text { swallowing in persons } \\
\text { with ALS }\end{array}$ & $\begin{array}{l}\text { University } \\
\text { of Florida, } \\
\text { USA }\end{array}$ & March 2019 \\
\hline NCT02851914 & $\begin{array}{l}\text { Open-Label Pilot } \\
\text { Study Comparing } \\
\text { the Efficacy of } \\
\text { Selective Serotonin } \\
\text { Re-Uptake } \\
\text { Inhibitors Versus } \\
\text { Tricyclic Anti- } \\
\text { depressants for } \\
\text { Treating Depression } \\
\text { in ALS }\end{array}$ & $\begin{array}{l}\text { To help to make } \\
\text { standard } \\
\text { recommendations in } \\
\text { treating depression in } \\
\text { ALS patients. }\end{array}$ & $\begin{array}{l}\text { St. Louis } \\
\text { University, } \\
\text { USA }\end{array}$ & December 2018 \\
\hline NCT02588807 & $\begin{array}{l}\text { Food Supplement } \\
\text { for the Treatment of } \\
\text { Patients With ALS }\end{array}$ & $\begin{array}{l}\text { To evaluate the safety } \\
\text { of combining } \\
\text { phospholipids with } \\
\text { medicinal plants for } \\
\text { treatment of patients } \\
\text { with ALS }\end{array}$ & $\begin{array}{l}\text { Herb Spirit } \\
\text { Carmel } \\
\text { Medical } \\
\text { Center, } \\
\text { Israel }\end{array}$ & May 2018 \\
\hline
\end{tabular}


Table 2.- Ongoing biomarkers clinical trials for ALS

\begin{tabular}{|c|c|c|c|c|}
\hline No. & Title & Stage & Sponsor & \begin{tabular}{|l|} 
Estimated Study \\
Completion Date
\end{tabular} \\
\hline NCT02559869 & $\begin{array}{l}\text { Imaging and BioFluid } \\
\text { Biomarkers in Amyotrophic } \\
\text { Lateral Sclerosis }\end{array}$ & Recruiting & $\begin{array}{l}\text { Massachusetts } \\
\text { General Hospital }\end{array}$ & May 2018 \\
\hline NCT02414230 & $\begin{array}{l}\text { F } 18 \text { T807 Tau PET Imaging in } \\
\text { Familial Amyotrophic Lateral } \\
\text { Sclerosis }\end{array}$ & Recruiting & $\begin{array}{l}\text { Washington } \\
\text { University } \\
\text { School of } \\
\text { Medicine }\end{array}$ & September 2020 \\
\hline NCT02405182 & MRI Biomarkers in ALS & Recruiting & $\begin{array}{l}\text { University of } \\
\text { Alberta }\end{array}$ & January 2020 \\
\hline NCT02885870 & $\begin{array}{l}\text { Combination of } \\
\text { Multiparametric MRI and } \\
\text { Electrophysiology for the } \\
\text { Development of New } \\
\text { Biomarkers in Spinal Cord } \\
\text { Diseases (SPINE2) } \\
\end{array}$ & Recruiting & $\begin{array}{l}\text { Institut de } \\
\text { Recherche sur la } \\
\text { Moelle épinière } \\
\text { et l'Encéphale }\end{array}$ & December 2016 \\
\hline NCT02874209 & $\begin{array}{l}\text { Noninvasive Assessment of } \\
\text { Neuronal Damage by MRI } \\
\text { Sodium ( 23Na ) in } \\
\text { Amyotrophic Lateral Sclerosis }\end{array}$ & Recruiting & $\begin{array}{l}\text { Assistance } \\
\text { Publique } \\
\text { Hopitaux De } \\
\text { Marseille }\end{array}$ & September 2018 \\
\hline NCT02424669 & $\begin{array}{l}\text { Neuroinflammation in } \\
\text { Amyotrophic Lateral Sclerosis } \\
\text { Mechanisms and Therapeutic } \\
\text { Perspectives: a Translational } \\
\text { Pilot Study Among ALS } \\
\text { Patients }\end{array}$ & Recruiting & $\begin{array}{l}\text { Assistance } \\
\text { Publique } \\
\text { Hopitaux De } \\
\text { Marseille }\end{array}$ & November 2018 \\
\hline
\end{tabular}


Table 3.- Ongoing cell therapy clinical trials for ALS

\begin{tabular}{|c|c|c|c|c|c|c|}
\hline Phase & No. & Cell type & $\begin{array}{c}\text { Type of } \\
\text { intervention }\end{array}$ & Stage & Sponsor & $\begin{array}{l}\text { Estimated Study } \\
\text { Completion Date }\end{array}$ \\
\hline 1 & NCT02286011 & $\begin{array}{l}\text { Autologous } \\
\text { Bone Marrow } \\
\text { Stem Cells in } \\
\text { Patients } \\
\end{array}$ & $\begin{array}{c}\text { Intramuscular } \\
\text { infusion }\end{array}$ & Recruiting & $\begin{array}{l}\text { Red de Terapia } \\
\text { Celular, Murcia, } \\
\text { Spain }\end{array}$ & January 2018 \\
\hline 1 & NCT02492516 & $\begin{array}{l}\text { Adipose } \\
\text { Derived } \\
\text { Mesenchymal }\end{array}$ & $\begin{array}{l}\text { Intravenous } \\
\text { injection }\end{array}$ & Recruiting & $\begin{array}{l}\text { Royan Institute, } \\
\text { Teheran, Iran }\end{array}$ & May 2016 \\
\hline $1 / 2$ & NCT02917681 & $\begin{array}{l}\text { Autologous } \\
\text { Mesenchymal } \\
\text { Stem Cells }\end{array}$ & $\begin{array}{l}\text { Intrathecal } \\
\text { injection }\end{array}$ & Recruiting & $\begin{array}{l}\text { University of } \\
\text { Sao Paulo } \\
\text { General } \\
\text { Hospital, Brasil }\end{array}$ & August 2019 \\
\hline $1 / 2$ & NCT02290886 & $\begin{array}{l}\text { Autologous } \\
\text { mesenchymal } \\
\text { stem cells }\end{array}$ & $\begin{array}{l}\text { Intravenous } \\
\text { injection }\end{array}$ & Recruiting & $\begin{array}{l}\text { Andalusian } \\
\text { Initiative for } \\
\text { Advanced } \\
\text { Therapies, } \\
\text { Spain } \\
\end{array}$ & February 2021 \\
\hline 1 & NCT02242071 & $\begin{array}{l}\text { Autologous } \\
\text { bone marrow } \\
\text { mononuclear } \\
\text { cells }\end{array}$ & $\begin{array}{c}\text { Cell } \\
\text { transplantation }\end{array}$ & Completed & $\begin{array}{l}\text { Neurogen Brain } \\
\text { and Spine } \\
\text { Institute }\end{array}$ & September 2016 \\
\hline $1 / 2$ & NCT02478450 & $\begin{array}{l}\text { Human Glial } \\
\text { Restricted } \\
\text { Progenitor Cells }\end{array}$ & $\begin{array}{c}\text { Cell } \\
\text { transplantation }\end{array}$ & Not yet open & $\begin{array}{l}\text { Q Therapeutics, } \\
\text { Inc. }\end{array}$ & December 2020 \\
\hline 2 & NCT02017912 & \begin{tabular}{|l|} 
Autologous \\
MSC-NTF Cells \\
(NurOwn)
\end{tabular} & $\begin{array}{c}\text { Cell } \\
\text { transplantation }\end{array}$ & Completed & $\begin{array}{l}\text { Brainstorm-Cell } \\
\text { Therapeutics }\end{array}$ & July 2016 \\
\hline 1 & NCT02943850 & $\begin{array}{l}\text { NS10-NPC- } \\
\text { GDNF for the } \\
\text { Treatment of } \\
\text { ALS }\end{array}$ & $\begin{array}{c}\text { Cell } \\
\text { transplantation }\end{array}$ & Not yet op & $\begin{array}{l}\text { Cedars-Sinai } \\
\text { Medical Center, } \\
\text { USA }\end{array}$ & April 2019 \\
\hline
\end{tabular}



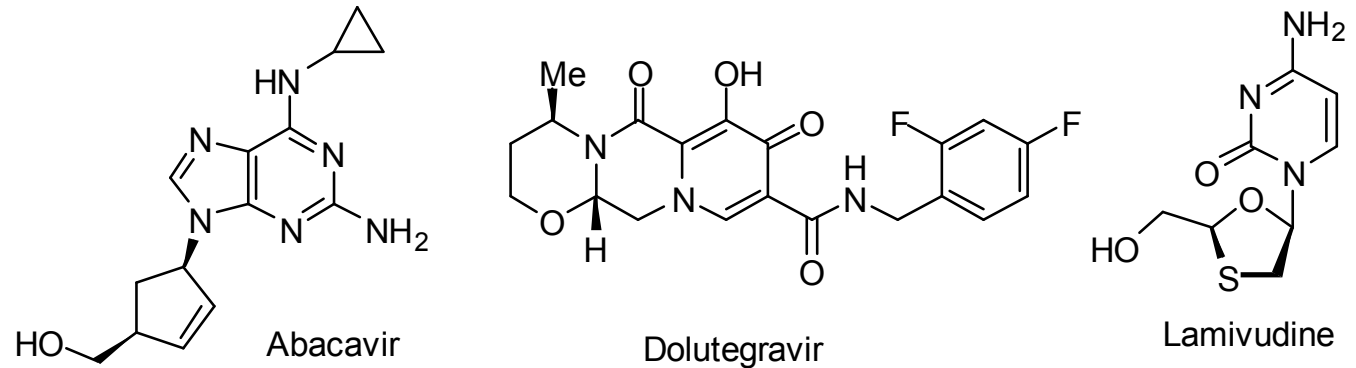

Figure 1. Chemical structure of the three drugs combined in Triumeq. 


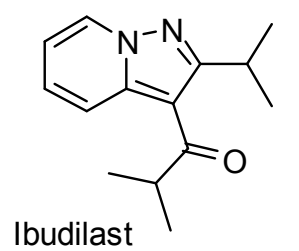<smiles>CC/C(=C(\c1ccccc1)c1ccc(OCCN(C)C)cc1)c1ccccc1</smiles><smiles>Cc1cccc(C)c1OCC(C)N</smiles><smiles>CC12CC3CC(C)(C1)CC(N)(C3)C2</smiles><smiles>CC1=NN(c2ccccc2)C(=O)C1</smiles>

Edaravone<smiles>CCCCCC[C@H]1SC[C@@H]2NC(=O)N[C@@H]21</smiles>
Memantine<smiles>CC1=C(C)[C@@H](CCC(N)=O)[C@@H](CC(N)=O)C1=C(C)C1=C(C)N(C)[C@](C)(CC(N)=O)[C@H]1CCC(N)=O</smiles>

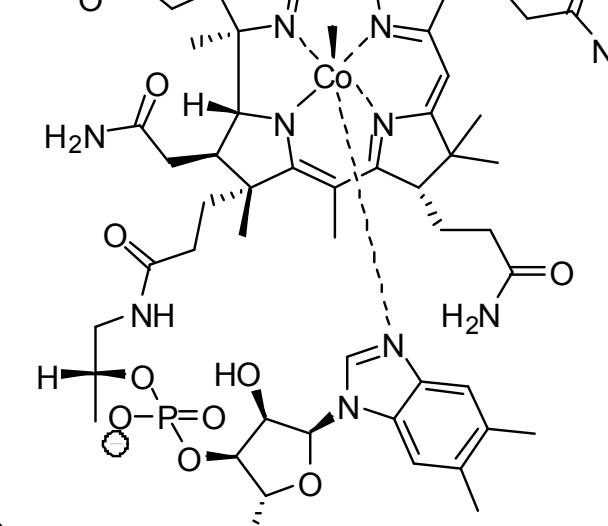

Biotin<smiles>C#CCNC1CCc2ccccc21</smiles><smiles>Cc1ccc(NC(=O)c2ccc(CN3CCN(C)CC3)cc2)cc1NC(=N)SS</smiles>
Methylcobalamin

Rasagiline<smiles>CCOC(C)(C)C</smiles>

Figure 2. Marketed drugs in clinical development for ALS therapy. 
<smiles>C#Cc1cnc2nc(O)n(C(CC)CC)c2n1</smiles>

Tirasemtiv<smiles>[O-][n+]1cccc(/C(Cl)=N/OC[C@@H](O)CN2CCCCC2)c1</smiles>

Arimoclomol<smiles>CC1(C)CC(=O)c2c(O)cc(O)cc2C1</smiles>

NP001

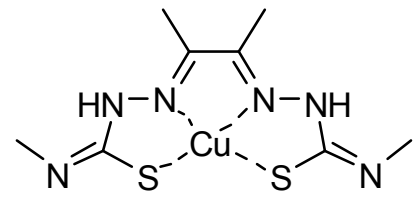

CUATSM

Figure 3. New drugs under clinical investigation for ALS treatment. 